\title{
Nutritional status assessment of the Polish Border Guards officers - Body Mass Index or Fat Mass Index?
}

\author{
Anna Anyzewska ${ }^{1}$, Roman Lakomy ${ }^{1}$, Tomasz Lepionka ${ }^{2}$, Ewa Szarska ${ }^{3}$, Ewelina Maculewicz ${ }^{3}$, \\ Izabela Bolczyk $^{4}$, Andrzej Tomczak ${ }^{5}$ and Jerzy Bertrandt ${ }^{1}$ \\ ${ }^{1}$ Laboratory of Food and Nutrition Hygiene, Military Institute of Hygiene and Epidemiology, Warsaw, Poland, \\ ${ }^{2}$ Laboratory of Food and Nutrition Hygiene, Military Institute of Hygiene and Epidemiology, Warsaw, Poland, \\ ${ }^{3}$ Laboratory of Physiology, Military Institute of Hygiene and Epidemiology, Warsaw, Poland, \\ ${ }^{4}$ The Polish Border Guard Headquarters, Warsaw, Poland and \\ ${ }^{5}$ The War Studies University in Warsaw, Faculty of National Security, Department of Security Education, Warsaw, \\ Poland
}

\begin{abstract}
Introduction: Border Guards service requirements are very specific. Very good health and excellent psycho-physical condition are the main factors that determine effectiveness and reliability of designated tasks. Disorders of nutritional status, such as underweight, overweight or obesity not only impairs well-being, but also are health problem associated with limitation of possibilities to perform Border Guard's tasks and duties and can lead to earlier elimination from the service. The aim of the study was to assess nutritional status, using two indicators: Body Mass Index (BMI) and Fat Mass Index (FMI).
\end{abstract}

Materials and methods: The study was carried out with participation of 259 Border Guards (64 women and 195 men), aged $38 \pm 6$; years of service: $12 \pm 6$. An electric bioimpedance method (TANITA MC-780) was used to determine body composition. Body Mass Index $\left(\right.$ BMI $\left[\mathrm{kg} / \mathrm{m}^{2}\right]=$ body mass $[\mathrm{kg}] /$ height $\left.{ }^{2}\left[\mathrm{~m}^{2}\right]\right)$ and Fat Mass Index FMI $\left[\mathrm{kg} / \mathrm{m}^{2}\right]=$ fat mass $\left.[\mathrm{kg}] / \mathrm{height}^{2}\left[\mathrm{~m}^{2}\right]\right)$ were calculated for each of the participants.

Results and discussion: Examined group of Polish Border Guards officers was characterized by a large variety of assessed anthropometric indicators. According to the BMI classification excess body mass was more often $(\mathrm{p}<0.001)$ observed in men $(68 \%)$ than in women $(25 \%)$ and according to the FMI classification excess fat was also more often $(\mathrm{p}<0.001)$ observed in men $(55 \%)$ than in women $(28 \%)$. BMI classification of overweight or obese was observed in 41 of participants with the normal FMI level. Fat percentage of women with normal BMI ranged from 11.6 to $33.5 \%$ and tat percentage of men with normal BMI ranged from 7.3 to $21.6 \%$. There are difficulties in BMI interpretation in adults with increased physical activity. It seems more reasonable to assess correctness of nutritional status on the basis of an analyze of FMI value, as this indicator assesses degree of fatness, and not the entire body weight, which, in case of uniformed services usually is greater due to extensive muscle mass, which can increase BMI value. It is necessary to take educational activities in the field of health promotion of these people, with a focus on nutrition prevention of metabolic civilization diseases, as well as to motivate Border Guards officers to respect basic principles of proper nutrition to maintain proper body mass and fat mass.

\section{Conflict of Interest}

There is no conflict of interest 